\title{
FINANCIAL ENGINEERING AS A TOOL FOR THE DEVELOPMENT OF CORPORATE BOND MARKET IN EASTERN EUROPE ON THE EXAMPLE OF UKRAINE
}

\author{
Maria Iorgachova ${ }^{1}$, Olena Kovalova ${ }^{2}$, Ivan Plets ${ }^{3}$
}

\begin{abstract}
In the context of the gap between the financial and real sectors of the Ukrainian economy, there is a problem of the absence of financial instruments able to solve the issue of financing the development of the national economic system on a long-term basis. At the current stage of the stock market development, financial engineering has a significant potential for the effective application since it can become an instrument that meets the current needs of the market. The purpose of this article is to study the current dynamics of development and features of the corporate bond market in Ukraine, as well as to develop the parameters of the new profit-bonds with the help of financial engineering, which takes into account investors' inquiries in the formation of an investment portfolio and supposed to be a profitable form of attracting financial resources for issuers. Methodology. Materials of periodicals, analytical market reviews, resources of the Internet are the informational and methodological basis of the investigation. The research is based on general scientific and special methods, such as: comparison, systematic approach factor analysis, economic and mathematical methods. A comparative analysis of the parameters of financial instruments has been carried out that allowed determining the investors' inquiries, investment trends and features of the choice of financial instruments by investors and accordingly to offer competitive debt securities according to the parameters of payment, maturity, security, repayment order, issue of currency. The results of the study indicate that there is the necessity of reformation of the stock market in terms of expanding the range of financial instruments based on financial engineering. The introduction of profit-bonds will allow offering participants of the Ukrainian market competitive conditions for the issue of securities, which are based on the modelled parameters of bonds. A schematic algorithm for the implementation of profit bonds is developed; it joins a complex of interrelated stages of implementation, which are sensitive to internal and external factors of influence. Practical implications. Directions for improving financial instruments on the basis of financial engineering can be applied by the participants of the stock market that will increase the general level of economic activity in the national economy and permit to accumulate financial resources on the profitable terms. Value/originality. The article reveals the development of the domestic market for corporate bonds as an important segment of the stock market through the application of financial engineering and the use of new financial products created to address the issue of attracting the necessary financial resources to the real sector. The introduction of financial engineering as a tool for the development of Ukrainian corporate bond market and its schematic algorithm of the implementation will allow an investor to react in time to the market changes. The creation of the State Fund for the Guaranteeing of Income of the Investors Market Act, which is formed at the state level by analogy with the existing Guarantee Fund for Individual Deposits, will allow the fulfilment of the security parameter that will classify profit bonds as long-term debt instruments with a high credit rating.
\end{abstract}

Key words: bond, financial engineering, stock market, issuer, investor.

JEL Classification: E44, G11, G39

\footnotetext{
Corresponding author:

${ }^{1}$ Odessa National Economic University, Ukraine.

E-mail: iorgachova@i.ua

ORCID: https://orcid.org/0000-0003-1933-6447

${ }^{2}$ Odessa National Polytechnic University, Ukraine.

E-mail: kovalova.helen@gmail.com

ORCID: https://orcid.org/0000-0002-2080-1150

${ }^{3}$ Vasyl Stefanyk Precarpathian National University, Ukraine.

E-mail: ivanplets86@ukr.net

ORCID: https://orcid.org/0000-0002-9649-6770
} 


\section{Introduction}

At the present stage of its development, the domestic financial market is closely connected with financial engineering. This linkage is especially clear in such an important segment of the financial market as the domestic stock market. The prerequisites for this connection and its strengthening in the future are the following:

- the prevalence of private placement of securities in the domestic stock market, which is marked by limited access to information about securities' transactions;

- existing financial instruments that are rotated on the domestic stock market are not capable of securing the goals and interests of some stock market participants, as there is a need for other financial instruments that have certain unique parameters and meet specific investors' interests;

- existing financial products already created, as a result of financial engineering, do not solve the problem of the gap between the financial sector and the corporate (real) sector of the country's economy;

- distrust of investors (both domestic and foreign) to Ukrainian issuers-borrowers and unsettled conflicts between stock market participants, as well as the ineffectiveness and imperfection of legislative regulation in this area.

All these preconditions lead to the fact that financial engineering can become a direction that will give extra opportunities to the further development of the domestic stock market. Consequently, it is necessary to analyse definite possible directions of implementation of products of financial engineering to the stock market and one must always take into account that if there is no connection with the real sector of the economy, any recommendations will have no real effect.

The work of such national scientists as O. Kuzmin and O. Sitnik are devoted to the study of theoretical and practical aspects of financial engineering, which reviewed the foreign experience of engineering activities. R. Isaev, S. Naumenkova, O. Paobov devoted their works to the application of financial engineering in the development of certain financial instruments in the stock market. A. Batorshina and V. Kravchenko considered the prospects of financial engineering development in Ukraine and in the world in general. Other foreign scholars such as J. Finneret and $\mathrm{R}$. Kosowski investigated the theoretical and practical aspects of financial engineering.

In general, one can note the lack of studying the use of financial engineering tools. The issues of resolving the gap between the application of financial engineering in the stock market and its simultaneous connection with the real sector of the economy remain unresolved. Consequently, the use of financial engineering in the context of creating new financial products in the securities market is a promising way of financing the real sector of the economy.

\section{Conceptualization of the correlation between the real and financial sectors of the economy}

The unstable socio-economic and political situation sharply raises the question of financing operational activities and implementing investment projects to the real sector of the economy. At the same time, individual and institutional investors are looking for financial instruments that meet the criteria of profitability and reliability. The current market conditions within the framework of the economic system, which is in the phase of its establishment, does not correspond to the requests of financial market participants in view of the uncertainty of investor protection issues, legislative and regulatory gaps and, accordingly, the narrow range of financial instruments available for investment. The experience of developed economic systems indicates the possibility of a revival of the market situation due to financial engineering.

According to the author, financial engineering in the corporate bond market is an instrument for the development of a new type of corporate bonds that simultaneously meet the needs of financial and real sector representatives and address the gap between these sectors and the increasing dominance of the financial sector.

When creating a financial product in the form of a new type of corporate bonds, it is necessary to determine the relationship between the number of bonds issued by enterprises in the market and the share of profitable enterprises. To do this, we will take advantage of the capabilities of the MS Excel software and visualize the results of the analysis based on data for the period of 2009-1 quarter of 2017 (Figure 1)

Each point in this graph is a combination of the number of corporate bonds issues and the percentage of profitable enterprises for the same period of the respective year. The line in the graph has a negative slope, indicating the existence of an indirect (reverse) connection between the number of lucrative enterprises and the number of bonds issued by enterprises. The relationship between the number of bonds issued by enterprises and the share of profitable enterprises can be expressed in the following equation:

$$
y=-20.435 x+1638.1
$$

where $y$ - the number of bonds issued by enterprises; $x$ - the share of profitable enterprises.

The abovementioned equation is a mathematical one-factor model for determining the number of bonds issued by enterprises from the share of profitable enterprises for the same period. From the equation, one can see that the zero factor is 1638.1 for the period that is the number of bond issues of enterprises expected if the share of profitable enterprises is zero. The sensitivity of the number of bonds issued by enterprises to the share of profitable enterprises is - 


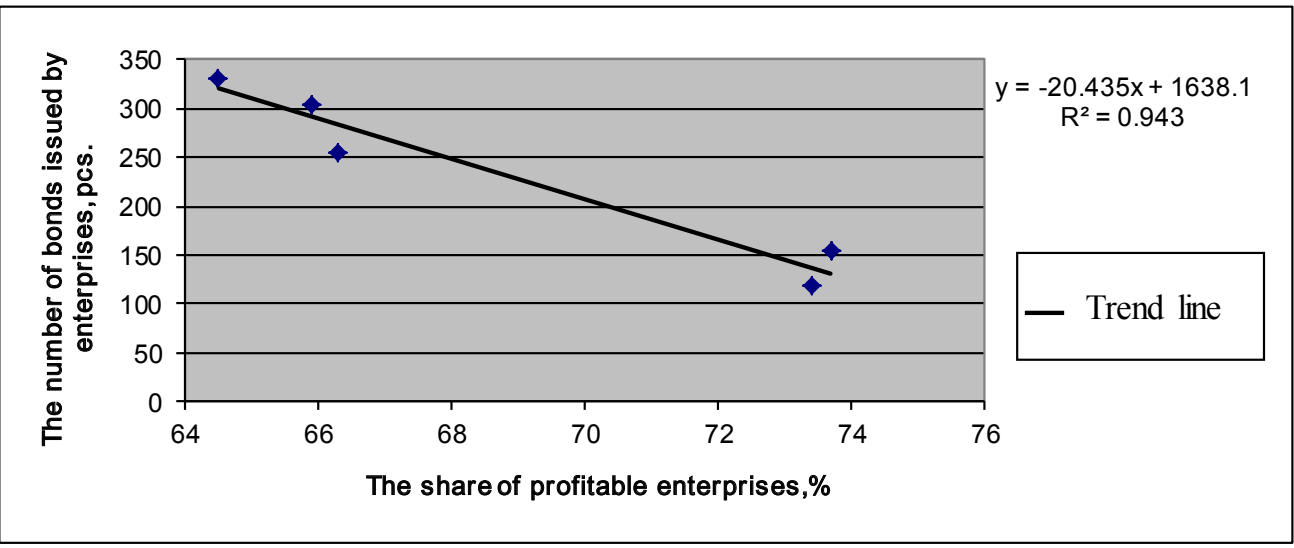

Figure 1. Graphic representation of the results of the analysis of the relationship between the number of bonds issued by enterprises and the share of profitable enterprises

Source: Built by the authors (the State Statistics Service of Ukraine and National Securities and Stock Market Commission, 2018)

20.435. This value indicates that the higher share of profitable enterprises is associated with fewer issues of corporate bonds. On the other hand, the smaller the share of profitable enterprises, the greater the issue of corporate bonds.

Consequently, the results of the analysis confirm that corporate bonds are a possible financial instrument necessary to be used for the enterprises of the real sector in order to attract the necessary financial resources in the period of their shortage. They have great potential for their development, but now they are used in the domestic stock market not sufficiently. Enterprises of the real sector of the economy, when they attract extra financial resources, tend to turn to the money market rather than to the stock market segment of the financial market. This is confirmed by the data of the State Statistics Service of Ukraine: only $7.1 \%$ of capital investments of enterprises are financed by bank loans, at the expense of other sources of financing $-2.3 \%$, that also include the attraction of resources in the securities market (State Statistics Service of Ukraine, 2018). The statistics presented are due to the insufficient distribution of the corporate bonds market in Ukraine - in 2016 its share in GDP was $0.4 \%$ against $8.86 \%$ of the market share of government bonds to GDP. Let's note the downward dynamics of these indicators compared to 2014: the share of corporate bonds to GDP $-2.16 \%$, the share of government bonds to GDP - 35.32\% (NSSMC, 2018). Consequently, summarizing all the above said, we can make the following conclusion: firstly, there is a strong ineffectiveness of the offered debt securities offered to the corporate sector in the corporate sector, which causes the insignificant demand of these financial instruments, and secondly, there is a strong ineffectiveness of the state reform of the stock market in terms of promoting the development of the securities market, which is declared in the Strategic Plan.

\section{Investments in financial market: characteristics of the current proposition}

The attractiveness of corporate bonds as a tool for investors to place free financial resources proves a comparative analysis of the main parameters of the most widely used financial instruments when diversifying the investment portfolio (Table 1).

The analysis of the peculiarities of issue of corporate bonds was carried out on the basis of construction industry enterprises since it was precisely in this area of the national economy as far as it was the largest market with the largest volume of securities issued for the 3rd quarter of 2016 in order to attract financial resources for certain projects, which is confirmed by data analysis of the industry structure of the largest bond issues (Figure 2). One can see the current situation due to the fact that the bonds of these enterprises are granted, and it allows investors to be sure in the safety of their investments. In accordance with the terms of the prospectus for the issue of targeted bonds, the investor, upon payment, receives the corresponding living space by transferring the object (a part of the object) to the ownership of the investor.

The active borrowers on the basis of debt securities were also enterprises operating in the field of supply of electricity, gas, steam and air-conditioned air, as well as companies of the agrarian sector. The identified structure of the largest bond issues reflects the peculiarities of the creation of the value added to the national economy, mainly in the third and fourth technological arrangements. According to the NCSSMF during January-December 2016, the financial sector companies did not issue any bonds; this indicates a decline in their economic activity. The opposite situation developed on the world stock market, where long-term bond funds typically choose for investments corporate bonds of companies, which operate in such sectors as the financial sector, telecommunication sector, and IT technologies. 
Vol. 4, No. 4, 2018

Table 1

Comparative characteristics of investment instruments by the end of the 1st quarter of 2017

\begin{tabular}{|c|c|c|c|c|}
\hline Indicators & $\begin{array}{c}\text { Domestic state bonds } \\
\text { (based on the example of } \\
\text { UA4000196562) }\end{array}$ & $\begin{array}{l}\text { Corporate sector bonds } \\
\text { (based on the example of } \\
\text { UA4000197230) }\end{array}$ & $\begin{array}{c}\text { Corporate sector bonds } \\
\text { (based on the example of } \\
\text { UA4000196018) }\end{array}$ & $\begin{array}{l}\text { Deposits to legal entities } \\
\text { in the national currency }\end{array}$ \\
\hline Profitability, \% & $15.50 \%$ & $\begin{array}{l}\text { Depends on the state of } \\
\text { the real estate market }\end{array}$ & $14 \%$ & $13.69 \%$ \\
\hline Period & $\begin{array}{c}\text { Medium-term securities } \\
2 \text { years }\end{array}$ & $\begin{array}{c}\text { Medium-term securities } \\
4 \text { years }\end{array}$ & $\begin{array}{c}\text { Medium-term securities } \\
\text { years }\end{array}$ & $\begin{array}{c}12 \text { months } \\
\text { long-term securities }\end{array}$ \\
\hline $\begin{array}{c}\text { Number of payments per } \\
\text { year }\end{array}$ & 2 times a year & 1 time a year & 12 times a year & 12 times a year \\
\hline Nominal value & $1000 \mathrm{UAH}$ & $315 \mathrm{UAH}$ & $100 \mathrm{UAH}$ & $100000 \mathrm{UAH}$ \\
\hline Listing level & 1 level & 0 level & 0 level & - \\
\hline Issuer & $\begin{array}{l}\text { Ministry of Finance of } \\
\text { Ukraine }\end{array}$ & $\begin{array}{l}\text { PJSC “ZOZNIAKI- } \\
\text { ZHIL-BUD” }\end{array}$ & $\begin{array}{l}\text { LLC "Mortgage Company } \\
\text { 'Arkada-Fund"” }\end{array}$ & $\begin{array}{c}\text { Average annual data on } \\
\text { NBU statistics }\end{array}$ \\
\hline $\begin{array}{c}\text { Kind of financial } \\
\text { instrument }\end{array}$ & Coupon bond & Target bond & Coupon bond & Timely deposit \\
\hline
\end{tabular}

Source: built by the authors (National Bank of Ukraine and First Stock Trading System, 2017)

For example, Long-Term Bond ETF holds the debt securities of British Telecommunications PLC, JPMorgan Chase \& Co, United Technologies Corp., Goldman Sachs Group Inc., Verizon Communications Inc., Apple Inc., and Microsoft Corp. (Database ETF, 2017).

\section{Algorithm for developing profit bonds}

The introduction of profit bonds will allow the participants of the Ukrainian financial market to compete with the issuance of securities based on simulated bonds, unlike deposits from commercial banks, where the terms of the contracts are fixed.

By the criterion of payment, profit bonds can be characterized by a floating coupon rate that allows taking into account cash flows of the issuer - the subject of management. It is advisable to apply a collar option on coupon bonds to minimize the risks of the issuer, which will include a base interest rate as the lower limit of coupon payment, and the upper limit is fixed in the prospectus at a certain level. It is proposed to link the base rate for the profit bond to the average market yield of bonds of a specific sector of the national economy, in which the issuer of securities operates financially and economically. Thus, the conjuncture factor and the inflationary effect will be taken into account. Unfortunately, the indexation of the exchange rate of yield is inaccessible for corporate issuers because of a list of reasons: firstly, in this case, they can carry unpredictable currency risks, and secondly, there is a methodological uncertainty about the choice of an indicator or an index of producer prices or the consumer index Prices, and thirdly, the instruments of influence on inflation are at the disposal of the relevant state authorities, which allows only the public sector to issue bonds with indexation to the rate of inflation.

As the PFTS Stock Exchange is the leader of bonds trading of enterprises on the basis of stock trading of 2016, according to the information of the NSSMC (it took

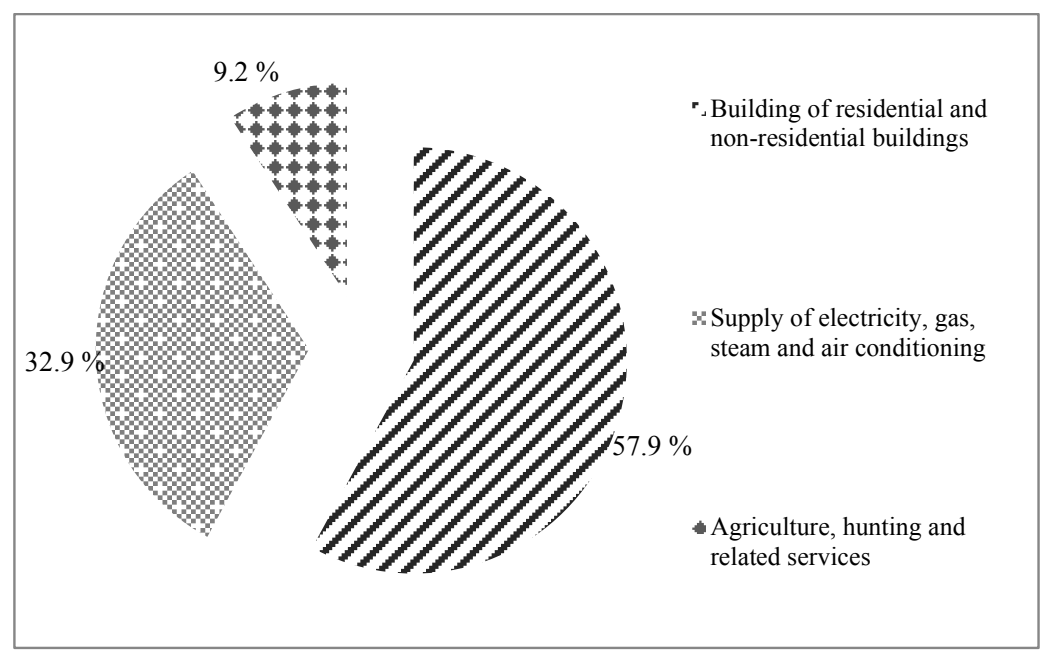

Figure 2. Branch structure of the largest bond issues in January-September 2016, \% Source: built by the authors (National Rating Agency "Rurik", 2018) 
$58.9 \%$ in the trading structure of bonds of enterprises as trade organizers) (National Securities and Stock Market Commission, 2018), it is expedient to calculate the yield of corporate bonds of each particular sector of the economy based on this stock market. It is inappropriate to determine the weighted average yield for all trade organizers since, at the moment, each stock exchange uses its own approaches to the calculation of indices.

According to the criterion of the issuance currency, it should be possible to issue two-digit profit bonds, which should attract attention to the issuers of export-import companies and provide investors with an additional opportunity to reinvest profits for speculative purposes.

In connection with a significant reduction in exports of goods by 1.7 times, imports -2 times during the period of 2014-2016, according to the NBU (National Bank of Ukraine, 2017), the two-digit Profit bonds will take into account the interests of both issuers and investors operating in the indicated sphere, financing of projects and diversification of investments.

Consequently, corporate profit bonds will be distinguished by the fact that the possible systematic risks will be divided equally between the issuer and the investor, in turn, the methodical principles of most of the already established financial engineering products, shift and transfer potential risks to the investor.

The parameter of the payment of profit bonds it is appropriate, in our opinion, to determine coupons issued 2 times a year based on the generally accepted in the stock market terms of payment, which will allow enough flexible approach to the question of formation of the income base and planning of financial and economic activity.

In accordance with the procedure for repayment of principal debt, profit bonds may be characterized by the depreciation of the principal amount of debt.

The presented parameter has advantages for the implementation from the point of view of investors in the conditions of socioeconomic instability, devaluation of the national currency, and is an actual proposal considering the long-term nature of the trading of profit bonds.

The reduction of the base of the coupon payment will be offset by the floating coupon rate, as well as the possibility of reinvestment of the received coupon payments and parts of the principal amount of the debt in the derivative financial instruments. In our opinion, it is a positive feature that allows an investor to react in time to the market changes and use the achievements of dynamic stock market development based on new financial engineering products.

In terms of security, the existing portfolio of assets in accordance with the law should guarantee the issue of profit bonds.

Currently, a timely development of the stock market in Ukraine is the creation of the State Fund for the Guaranteeing of Income of the Investors Market Act, which is formed at the state level by analogy with the existing Guarantee Fund for Individual Deposits.
The fulfilment of the security parameter will allow profit bonds to be classified as long-term debt instruments with a high credit rating.

According to the NRA "Rurik" (National Rating Agency "Rurik", 2018), today in Ukraine debt instruments with a credit rating prevail, which defines a sufficient level of creditworthiness of the borrower.

These are bonds of companies the branch affiliation of which provides the following activities in accordance with CRED: business advisory and management consultancy, building construction, accounting and auditing activities, brokering activities in the wide range of trade in goods, non-specialized wholesale trade, other auxiliary activities in insurance and pensions.

However, it should be noted that on the one hand, the bonds were assigned the $\mathrm{BBB}$ rating, and on the other hand, a number of them are unsecured in accordance with the prospectus (AvtoFinanceService Ltd, Modern Financial Service LLC, Business Innovation Company Ltd.). Thus, one can observe the absence of a direct link between security and a credit rating of the security.

According to an analysis conducted by the RurikNRA, in the debt securities market, the largest share of issuers is sensitive to unfavourable commercial, financial, and economic conditions in line with long-term borrowing ratings (National Rating Agency "Rurik”, 2018).

Thus, as of July 6, 2017, in the structure of the PFTS stock exchange, there are no corporate debt securities of level 1 of the listing. Up to 2 levels of listing include bonds of the largest enterprises in its industry, namely Ukrtelecom PJSC, Egres-Agro TOV, SE "NNEGC 'Energoatom'”, Energorynok, Ukrzaliznytsia PJSC, Progress Plus.

In addition to the parameters of the new financial product, it is also advisable to find out the algorithm of its development, which consists of five stages (Figure 3 ).

These phases are interrelated and take into account factors of environmental impact and are sensitive to changes in the motives of investor acquisition of securities. A particular attention should be paid to the fifth stage, because even if all the previous stages were successfully implemented and the financial instrument was introduced to the stock market, the modification of the parameters and characteristics of the new financial instrument, which will be reflected in the next issue of securities of the respective issuers, is possible.

\section{Conclusions}

The conducted analysis of the debt securities market pointed to the peculiarities of its development and identified the following weaknesses:

1. The problem of non-compliance of the existing parameters of financial instruments with the needs of the subjects of the investment market and the lack of a unified scientific and methodical approach to the processes of constructing their new parameters. 
1. Selection of specific features of a new type of corporate bonds that would address existing problems and satisfy the needs of a particular group of consumers-investors

2. Development of parameters for a new type of corporate bonds (profit-bonds)

3. Checking and testing a new financial instrument among the focus group of people interested in this direction

4. Implementation of a new type of corporate bonds on the domestic stock market

5. Modification of the created product depending on changes in the market environment

Figure 3. Algorithm for developing a new type of corporate bonds (profit bonds)

Source: built by the authors

2. The share of corporate bonds in the stock exchange structure is insignificant compared to other financial instruments, which prevent them from acting as a central component of the stock market, which can become a prerequisite for the development of the national economy.

3. Absence at the state level of the mechanism of protection of investors' assets, which explains the necessity for creating the State Fund of guaranteed income of subjects of the investment market.

Financial engineering should become the basis for the formation of corporate bonds in an affordable source of accumulation of financial resources by the real sector of the economy due to the implementation of its tools and, accordingly, modelling the parameters of new types of debt securities, among which the emphasis should be placed on the constructed profit bonds research, having a series of advantages and correspond to the actual market needs.

The prospect of further research is the analysis of foreign experience as for the use of financial engineering tools and the substantiation of the mechanism for the creation and introduction into the domestic market of the State Fund for the Guaranteeing of Revenues of the Investors Market Investors, which will facilitate the resolution of issues related to the development of the financial market.

\section{References:}

Database ETF (2017). Retrieved December 16, 2017 from: http:/ / etfdb.com/

National Bank of Ukraine (2017). Retrieved December 16, 2017 from: http://www.bank.gov.ua/

National Rating Agency "Rurik” (2018). Retrieved May 16, 2018 from: http://rurik.com.ua/

National Securities and Stock Market Commission (2018). Retrieved February 10, 2018 from: http://www.nssmc.gov.ua/

State Statistics Service of Ukraine (2018). Retrieved May 16, 2018 from: http://www.ukrstat.gov.ua/

The First Stock Trading System (2017). Retrieved December 16, 2017 from: http://www.pfts.ua/ 